\title{
Interleukin-17 Promotes Early Allograft Inflammation
}

\author{
Victoria Gorbacheva, Ran Fan, Xiaoxia Li, \\ and Anna Valujskikh \\ From the Department of Immunology, The Cleveland Clinic, \\ Cleveland, Ohio
}

Acute cellular rejection of organ transplants is executed by donor-reactive $T$ cells, which are dominated by interferon- $\gamma$-producing cells. As interferon- $\gamma$ is dispensable for graft destruction, we evaluated the contribution of interleukin-17A (IL-17) to intragraft inflammation in major histocompatibility complex-mismatched heart transplants. $\mathbf{A} / \mathbf{J}\left(\mathbf{H}-2^{a}\right)$ cardiac allografts placed into wild-type BALB/c (H-2 $\left.{ }^{d}\right)$ mice induced intragraft IL-17 production on day 2 after transplant. Allografts placed into BALB/c $\mathrm{IL}-17^{-/-}$recipients demonstrated diminished production of the chemokines CXCL1 and CXCL2 and delayed neutrophil and $T$ cell recruitment. However, by day 7 after transplant, allografts from IL-17 $7^{-/-}$and wild-type recipients had comparable levels of cellular infiltration. The priming of donor-specific $T$ cells was not affected by the absence of IL-17, and the kinetics of cardiac allograft rejection were similar in wild-type and $\mathrm{IL}-17^{-/-}$recipients. In contrast, $\mathrm{IL}-17^{-/-}$mice depleted of $\mathrm{CD8} \mathrm{T}$ cells rejected $\mathbf{A} / \mathbf{J}$ allografts in a delayed fashion compared with CD8-depleted wild-type recipients. Although donorreactive CD4 $\mathrm{T}$ cells were efficiently activated in both groups, the infiltration of effector $T$ cells into allografts was impaired in $\mathrm{IL}-17^{-/-}$recipients. Our data indicate that locally produced IL-17 amplifies intragraft inflammation early after transplantation and promotes tissue injury by facilitating $T$ cell recruitment into the graft. Targeting the IL-17 signaling network in conjunction with other graft-prolonging therapies may decrease this injury and improve the survival of transplanted organs. (AmJ Pathol 2010, 177:1265-1273; DOI: 10.2353/ajpath.2010.091106)

Despite the increasing quality of immunosuppression, acute cellular rejection episodes occur in more that half of solid organ transplants. Acute allograft rejection is initiated and executed by alloreactive T cells primed in peripheral lymphoid organs and recruited to the graft. Donor-specific $\mathrm{T}$ cell responses following transplantation are typically dominated by interferon (IFN) $\boldsymbol{\gamma}$-producing cells. ${ }^{1-3}$ However, IFN $\gamma$ is dispensable for graft destruction, indicating that other cytokines may contribute to the inflammation cascade and facilitate rejection. ${ }^{4-6}$

Interleukin (IL)-17 (also called IL-17A) is a pleiotropic cytokine with multiple pro-inflammatory functions. Due to the ubiquitous expression of IL-17R, IL-17 can target many different cell types including epithelial and endothelial cells, fibroblasts, and macrophages, and orchestrate tissue inflammation. ${ }^{7,8}$ A signature downstream effect of IL-17 is the recruitment and activation of neutrophils and monocytes. IL-17 plays a critical role in host defense against bacterial and fungal pathogens including Klebsiella pneumoniae, Listeria monocytogenes, and Candida albicans., ${ }^{7-11}$ Increased expression of $\mathrm{IL}-17$ is observed in patients with autoimmune disorders such as multiple sclerosis, rheumatoid arthritis, psoriasis, and inflammatory bowel disease. ${ }^{12,13}$ Rodent studies have confirmed the involvement of IL-17 in the pathogenesis of autoimmune diseases that were traditionally thought to be IFN $\gamma$ - and Th1-dependent, including experimental autoimmune encephalomyelitis and collagen-induced arthritis. ${ }^{14-17}$

Recent data from clinical and experimental transplantation suggest the involvement of IL-17 in allograft rejection. For example, IL-17 mRNA and protein expression are elevated in human renal and lung allografts during acute rejection episodes. ${ }^{18-20}$ In experimental transplantation, increased intragraft IL-17 levels have been observed in animal models of heart and renal allograft rejection. ${ }^{19}$ In addition, two groups have reported that IL-17-producing cells mediate cardiac allograft rejection in mice unable to mount Th1 alloimmune responses. ${ }^{21-23}$ The potential significance of $\mathrm{IL}-17$ in transplantation is further underscored by findings that a neutralizing IL17R-Ig fusion protein reduced intragraft production of IFN $\gamma$ and prolonged survival of heart and aorta transplants in rodent models. ${ }^{24,25}$ However, the temporal appearance and the role of $\mathrm{IL}-17$ in allograft rejection by wild-type recipients under normal physiological conditions as well as the nature of cooperation between donor-

Supported by R01 AI058088-01A3 from the NIH (A.V.).

Accepted for publication May 27, 2010.

Address reprint requests to Anna Valujskikh, Ph.D., Department of Immunology, NB-30, Lerner Research Institute, The Cleveland Clinic, 9500 Euclid Ave, Cleveland, OH 44195. E-mail: valujsa@ccf.org. 
specific CD4 and CD8 T cells producing IL-17 and IFN $\gamma$ remain largely undefined.

In this study, we evaluated the contribution of IL-17 to the induction and amplification of inflammation in class I and class II major histocompatibility complex (MHC)mismatched murine heart allografts. Our findings indicate that IL-17 up-regulates neutrophil chemoattractant molecules and enhances early neutrophil influx into allografts thus facilitating further recruitment of pathogenic IFN $\gamma$ producing $T$ cells into the graft.

\section{Materials and Methods}

\section{Animals}

Male and female BALB/c $\left(H-2^{d}: K^{d}, D^{d}, L^{d}, I-A^{d}\right.$, and $\left.\mathrm{I}-\mathrm{E}^{\mathrm{d}}\right), \mathrm{A} / \mathrm{J}\left(\mathrm{H}-2^{\mathrm{a}}: \mathrm{K}^{\mathrm{k}}, \mathrm{D}^{\mathrm{d}}, \mathrm{L}^{\mathrm{d}}, \mathrm{I}-\mathrm{A}^{\mathrm{k}}\right.$, and $\left.\mathrm{I}-\mathrm{E}^{\mathrm{k}}\right)$, and $\mathrm{C} 57 \mathrm{BI} / 6$ (B6, $\mathrm{H}-2^{\mathrm{b}}: \mathrm{K}^{\mathrm{b}}$, $\mathrm{D}^{\mathrm{b}}$, and $\mathrm{I}-\mathrm{A}^{\mathrm{b}}$ ) mice, aged 6 to 8 weeks, were purchased from the Jackson Laboratories (Bar Harbor, ME). IL-17 ${ }^{-1-}$ (knockout $[\mathrm{KO}]$ ) mice on the BALB/c background were provided by Dr. Iwakura (University of Tokyo, Tokyo, Japan). All animals were maintained and bred in the pathogen-free facility at The Cleveland Clinic. All procedures involving animals were approved by the Institutional Animal Care and Use Committee.

\section{Placement and Evaluation of Cardiac Allografts}

Vascularized heterotopic cardiac allografts were placed and monitored as previously described. ${ }^{26}$ Rejection was defined as a loss of palpable heartbeat and was confirmed by laparotomy. In selected experiments, recipient CD8 T-cells were depleted by using a cocktail of TIB105 and YTS169 anti-CD8 monoclonal antibodies (BioXCell, West Lebanon, $\mathrm{NH}$; $0.2 \mathrm{mg}$ each i.p. on days $-3,-2,-1$, 5 , and 10 post transplant). Portions of graft tissue were embedded in OCT compound (Sakura Finetek USA, Torrance, CA). Frozen sections were fixed in cold acetone, air dried, hydrated in PBS for 10 minutes, and stained for 30 minutes with the following monoclonal antibodies at $10 \mu \mathrm{g} / \mathrm{ml}$ : GK1.5 for $\mathrm{CD}^{+}$cells, 53.6 .72 for $\mathrm{CD}^{+}$ cells, F4/80 for macrophages, and RB6-8C5 for GR-1 ${ }^{+}$ polymorphonuclear cells (PMNs; all from BD Biosciences, San Jose, CA). After additional washes with PBS, the sections were incubated for 20 minutes with biotinylated rabbit anti-rat IgG (Dako Corporation, Carpinteria, CA) at 1:300 dilution. The slides were incubated with Streptavidin-HRPO conjugate (Dako Corporation) and developed with diaminobenzidine substrate (Vector Laboratories, Inc., Burlingame, CA) and counterstained by immersion in hematoxylin for 2 minutes. Images were captured and analyzed with Image-Pro Plus (Media Cybernetics, Silver Spring, MD).

\section{Isolation of Graft-Infiltrating Cells}

Recipients were anesthetized and injected i.v. with 10 to $15 \mathrm{ml}$ of sterile PBS until all organs were blanched. Heart grafts were minced and digested with collagenase IV at 1 $\mathrm{mg} / \mathrm{ml}$ (Sigma-Aldrich, Saint Louis, $\mathrm{MO}$ ) at $37^{\circ} \mathrm{C}$ for 30 minutes with gentle intermittent vortexing. After incubation, the suspensions were filtered through $40-\mu \mathrm{m}$ cell strainers to remove larger pieces of residual tissue. Resultant cells were washed, counted, and analyzed by flow cytometry or enzyme linked immunosorbent spot (ELISPOT) assay.

\section{Flow Cytometry}

Phycoerythrin-conjugated anti-mouse F4/80 and allophycocyanin-conjugated anti-mouse CD8 were purchased from eBioscience (San Diego, CA). Fluorescein isothiocyanate-conjugated anti-mouse CD4 and fluorescein isothiocyanate-conjugated anti-mouse Ly-6G (Gr-1) were purchased from BD Biosciences. Cells isolated from spleens or heart allografts were stained with indicated antibodies as previously described ${ }^{27-29}$ and analyzed on a BD Biosciences FACSCalibur by using CellQuest software.

\section{ELISPOT Assay}

Assays were performed as previously outlined by using capture and detecting anti-mouse IFN $\gamma, \mathrm{IL}-17$, and IL-4 antibody from BD Biosciences. ${ }^{30}$ Spleen or graft-infiltrating cells were stimulated with mitomycin C-treated donor A/J or third party B6 spleen cells for 24 hours. The resulting spots were analyzed by using an ImmunoSpot Series 2 Analyzer (Cellular Technology Ltd., Cleveland, OH).

\section{Adoptive Transfer of Effector T Cells}

To generate alloreactive effector T cells, full-thickness A/J donor trunk skin was transplanted onto wild-type BALB/C recipient mice. After 12 days, draining lymph nodes were isolated, and single cell suspension was prepared and passed through negative selection $\mathrm{T}$ cell isolation columns (R\&D Systems, Minneapolis, MN). The resultant cells were labeled with $5 \mu \mathrm{mol} / \mathrm{L}$ carboxyfluorescein succinimidyl ester (Molecular Probes, Eugene, OR) for 10 minutes at room temperature, washed 3 times with PBS, and injected intravenously into wild-type BALB/c or IL-17 $\mathrm{KO}$ recipients of $\mathrm{A} / \mathrm{J}$ heart transplants on day 2 after transplantation ( $15 \times 10^{6}$ cells/mouse). Recipients were sacrificed 24 hours after cell injection, and graft-infiltrating cells were isolated by collagenase digestion and evaluated by flow cytometry.

\section{RNA Isolation and Quantitative Real-Time PCR Analysis}

Harvested heart grafts were immediately frozen by immersion into liquid nitrogen. Total RNA was isolated from individual samples by using TriZol reagent (Invitrogen, Carlsbad, CA) according to the manufacturer's protocol. Reverse transcription was performed by using the HighCapacity cDNA Reverse Transcription Kit; quantitative real-time PCR was done on a 7500 Fast Real-Time PCR 
System instrument by using Taqman Fast Universal PCR Master Mix (2X), No AmpEraseUNG (all from Applied Biosystems, Foster City, CA) following the manufacturer's instructions. Probes and primers were from Taqman gene expression assay reagents (Applied Biosystems). The following Taqman expression assays were used: IL-17 (Mm00439619_m1), IFNy (Mm00801778_m1), CD3 (Mm00599683_m1), CXCL1 (Mm004323859_m1), CXCL2 (Mm0436450_m1), and CCL2 (Mm00441242_m1). Data were normalized to Mrpl 32 RNA amplification level in each sample and calculated relative to the expression of the target gene in native heart tissue.

\section{Protein Purification and Chemokine Enzyme-Linked Immunosorbent Assay}

Snap-frozen grafts were homogenized in $0.5 \mathrm{ml}$ of icecold PBS/0.01 M EDTA plus protease inhibitors cocktail (Sigma) by using Polytron homogenizer. After homogenizing, $1 \mathrm{ml}$ of $1.5 \%$ Triton $\mathrm{X}-100$ in PBS was added to each sample followed by 30 minutes of incubation at $4^{\circ} \mathrm{C}$ and centrifugation at $12,000 \mathrm{~g}$ for 10 minutes. Total protein concentration was measured in supernatants by using bicinchoninic acid assay (Pierce, Rockford, IL). The concentrations of CXCL1, CXCL2, and CCL2 chemokines in lysates were measured by enzyme-linked immunosorbent assay by using capture, detection antibodies, and standards purchased from R\&D Systems. The assay was performed according to the manufacturer's protocol.

\section{Statistical Analysis}

Heart allograft survival was compared between groups by using Kaplan-Meier analysis. The results of immune recall responses, real time PCR, and flow cytometry assays were analyzed by using nonparametric Mann-Whitney test; a $P$ value $<0.05$ was considered a significant difference. Unless noted otherwise, the data are represented as mean values $\pm \mathrm{SD}$.

\section{Results}

\section{IL-17 Is Expressed in the Graft after Transplantation}

To determine whether IL-17 is produced in heart allografts, we analyzed the kinetics of IL-17 mRNA expression within class I and class II MHC mismatched $\mathrm{A} / \mathrm{J}$ allografts and syngeneic grafts placed into BALB/C recipients. IL-17 mRNA expression was up-regulated in the allografts as early as 2 days after transplant, reached peak levels by day 4 , and declined by the time of graft rejection. Heart isografts induced similar kinetics of IL-17 mRNA expression, albeit about 10-fold lower levels than those in allografts at all time points (Figure 1A). ELISPOT analysis of graft infiltrating cells (GICs) confirmed the presence of IL-17 secreting cells at a frequency of $85 \pm$ $34 / 1 \times 10^{6}$ on day 4 with subsequent increase to $470 \pm$ $82 / 1 \times 10^{6}$ by day 7 after transplant (Figure $1 \mathrm{~B}$ and data
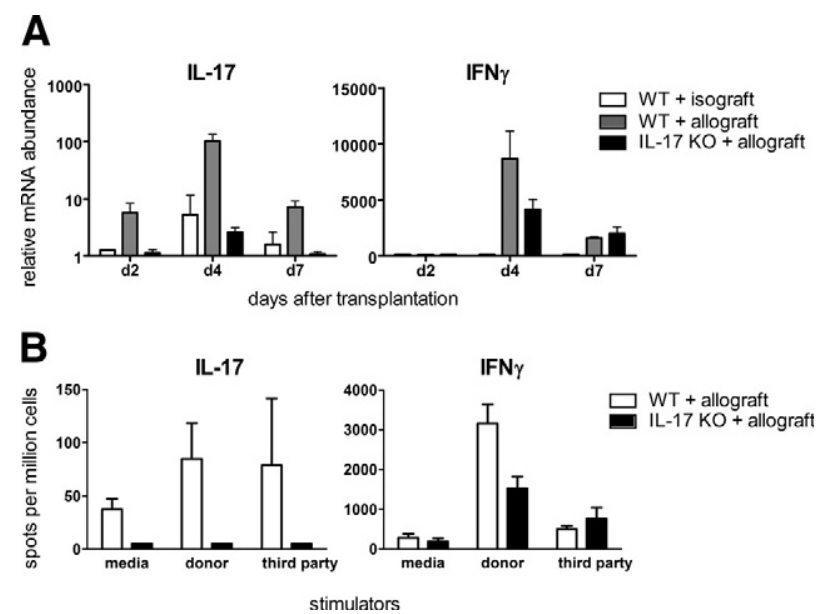

Figure 1. IL-17 is expressed in heart iso- and allograft. Groups of BALB/c or IL-17 KO mice received syngeneic or MHC mismatched A/J cardiac allografts ( $n=4$ to 5 per group). A: Heart grafts were harvested two, four, and seven days after the transplantation, and IL-17 and IFN $\gamma$ mRNA expression was determined by quantitative real-time PCR. B: Graft infiltrating cells were isolated by collagenase digestion on day four after transplantation and tested in a recall IL-17 and IFN $\gamma$ ELISPOT assays against donor A/J or third party B6 stimulator cells. Each experiment was performed twice with similar results.

not shown). Minimal IL-17 mRNA expression and the absence of IL-17 secreting cells in recall ELISPOT assay $(<5 \mathrm{IL}-17$ secreting cells per million GICs) in wild-type allografts placed into IL-17 KO recipients suggested that recipient infiltrating cells are the main source of intragraft IL-17. Although there was a temporal correlation between IL-17 and IFN $\gamma$ mRNA levels in the graft, the magnitude of IFN $\gamma$ expression and the frequencies of IFN $\gamma$-secreting graft-infiltrating cells were significantly higher (Figure 1), consistent with the predominance of IFN $\gamma$-producing $\mathrm{T}$ cells during allograft rejection.

\section{Early Neutrophil Infiltration Is Reduced in IL-17 KO Allograft Recipients}

A signature inflammatory effect of IL-17 is the recruitment and activation of neutrophils and monocytes. ${ }^{7}$ This recruitment is directed by IL-17 induced neutrophil chemoattractants Gro- $\alpha$ (CXCL1) and MIP-2 (CXCL2) and the macrophage chemoattractant MCP-1 (CCL2). In the initial set of experiments, we placed $\mathrm{A} / \mathrm{J}$ heart allografts into wild-type and IL-17 KO recipients and evaluated early intragraft expression of chemokine mRNA and protein. On days 2 and 4 after transplantation, heart allografts in IL-17 KO recipients expressed decreased levels of CXCL1 and CCL2 compared with allografts retrieved from wild-type recipients (Figure 2A). We next examined whether the decreased chemokine production led to reduced neutrophil and macrophage infiltration into heart allografts. Histological analyses of graft tissue revealed significantly lower numbers of graft-infiltrating $\mathrm{Gr}-1^{+}$cells in IL-17 KO recipients compared with wild-type mice (Figure 2B). The flow cytometry analyses of graft-infiltrating cells confirmed that heart allografts from IL-17 KO recipients contained lower numbers of neutrophils and macrophages (Figure 2C). These results suggest that $\mathrm{IL}-17$ induces neutrophil and macrophage chemoattrac- 
A
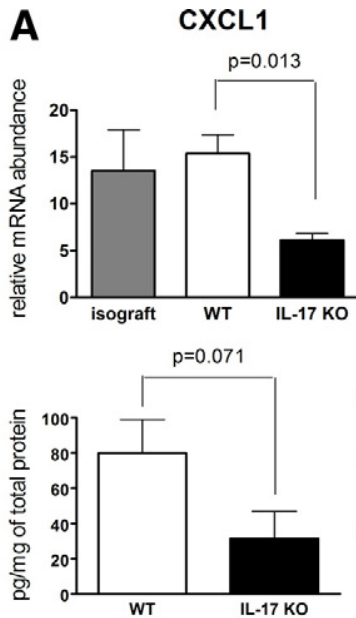

B

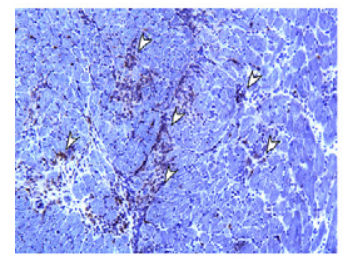

WT recipients

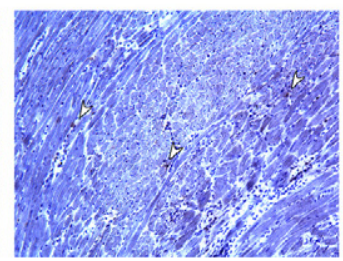

IL-17 KO recipients
CXCL2
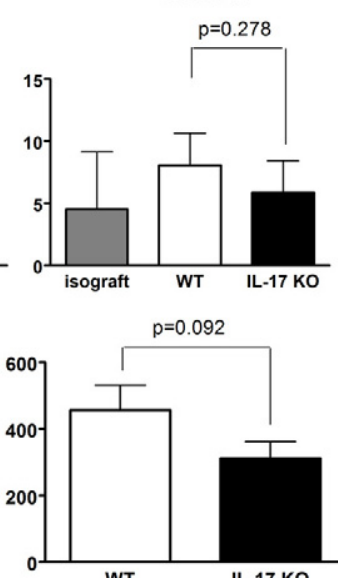

IL-17 KO
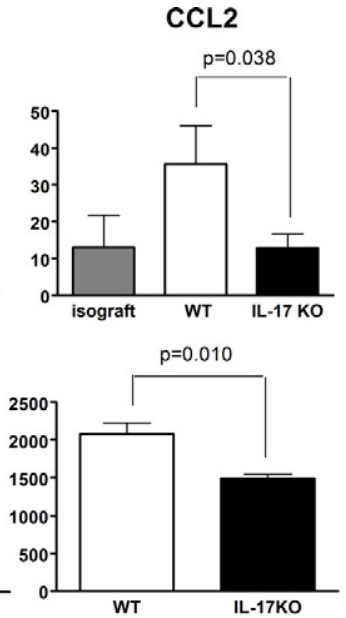
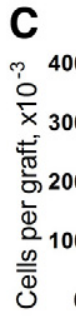

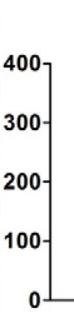

$\square$ WT

$$
\text { IL-17 KO }
$$
$p=0.050$

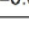

Figure 2. Expression of neutrophil-attracting chemokines and early neurophil infiltration are reduced in IL-17 KO heart allograft recipients. A: Intragraft chemokine expression. Total RNA was isolated from heart grafts harvested two days after the transplantation, and chemokine mRNA expression was determined by real-time PCR. Protein lysates were prepared from heart allografts on day four after transplantation and chemokine concentration was measured by enzyme-linked immunosorbent assay. The results are shown as amount of chemokine per milligram of total protein. B Immunohistochemical staining of $\mathrm{Gr}^{-}{ }^{+}$cells on day four after transplant. Arrows indicate foci of positively stained cells. The sections are representative of six to eight recipients per group. Original magnification, $\times 100$. C: Graft infiltrating cells were isolated on day four after transplantation and analyzed by flow cytometry for the expression of Gr-1 and $\mathrm{F} 4 / 80$ markers. The data are represented as numbers of positive cells per graft. The experiment was performed twice with similar results.

tants and facilitates recruitment of PMNs and macrophages into cardiac allografts.

\section{T Cell Recruitment into Cardiac Allografts Is Delayed in IL-17 KO Recipients}

Intragraft inflammation and tissue damage mediated by PMNs facilitates the recruitment of alloreactive T cells into the graft. ${ }^{31}$ In parallel with the diminished infiltration of neutrophils, fewer $\mathrm{CD}^{+}$and $\mathrm{CD}^{+}$cells were observed on day 4 after transplant in allografts from $\mathrm{IL}-17 \mathrm{KO}$ versus wild-type recipients (Figure 3A). Quantitative realtime PCR and flow cytometry analyses confirmed that levels of CD3 and IFN $\gamma$ mRNA expression as well as total numbers of infiltrating $\mathrm{CD}^{+}$and $\mathrm{CD}^{+}{ }^{+} \mathrm{T}$ cells were reduced in grafts from $\mathrm{IL}-17 \mathrm{KO}$ recipients (Figure $3 \mathrm{~B}$ and $\mathrm{C}$ ).

Despite the difference in early PMN and T cell infiltration, $T$ cell allograft infiltration was similar in wild-type and $\mathrm{IL}-17 \mathrm{KO}$ recipients by day 7 after transplant (Figure 4A). To support the histological findings, graft-infiltrating cells were isolated from collagenase-digested graft tissue on day 7 after transplantation and analyzed by flow cytometry and ELISPOT assay. Numbers of graft infiltrating CD8 T cells, CD4 T cells, and neutrophils were comparable in wild-type and IL-17 $\mathrm{KO}$ recipients (Figure 4B). Furthermore, heart allografts from both sets of recipients revealed similar numbers of donor-specific $T$ cells producing IFN $\gamma$ (Figure 4C). Consistent with these results, wild-type and IL-17 KO BALB/c mice rejected A/J cardiac allografts with similar kinetics (median survival time of $7.3 \pm 1.4$ days and $7.5 \pm 0.9$ days, respectively; Figure 5). Thus, the diminished inflammation at early time points after transplant did not translate into prolonged cardiac allograft survival in IL-17 KO recipients.

\section{Delayed CD4 T Cell Mediated Allograft Rejection in IL-17 KO Recipients}

Donor-reactive CD8 T cells primed by cardiac allografts are detected in the spleen by day 4 after transplant and are rapidly recruited to the graft site. The hallmark function of graft-infiltrating CD8 T cells is the secretion of IFN $\gamma$ that in turn augments production of chemokines and further leukocyte recruitment. ${ }^{32}$ We reasoned that the potent inflammation evoked by CD8 T cells arriving into the graft between days 4 and 7 after transplantation may compensate for the absence of $\mathrm{IL}-17$ in heart allograft recipients. To test this, we examined the role of $\mathrm{IL}-17$ in CD4 T cell-mediated heart allograft rejection.

Groups of wild-type and IL-17 KO BALB/c recipients were depleted of CD8 T cells and transplanted with A/J heart allografts. Consistent with previous reports, ${ }^{33,34}$ CD4 T cells efficiently mediated cardiac allograft rejection in wild-type recipients by day 8 after transplant. Recipient deficiency in IL-17 resulted in a modest, but statistically significant, prolongation of graft survival (Figure 6A). Flow cytometry analyses of spleen and graftinfiltrating cells at the time of rejection confirmed the effectiveness of CD8 T cell depletion, implicating CD4 T cells as major mediators of graft rejection under these conditions (Figure 6B).

Recipient IL-17 deficiency resulted in the reduced expression of intragraft chemokine proteins and in the decreased infiltration of neutrophils and macrophages on day 4 after transplantation (Figure 7A and data not 
A
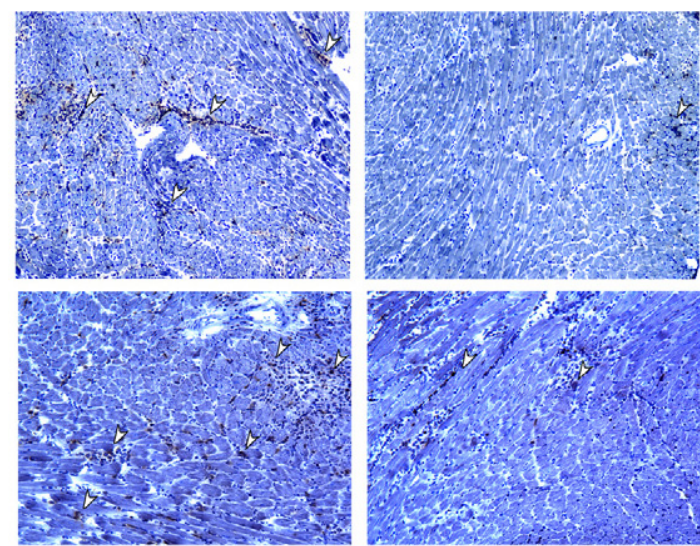

WT recipients

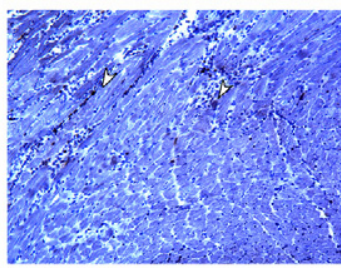

IL-17 KO recipients

B

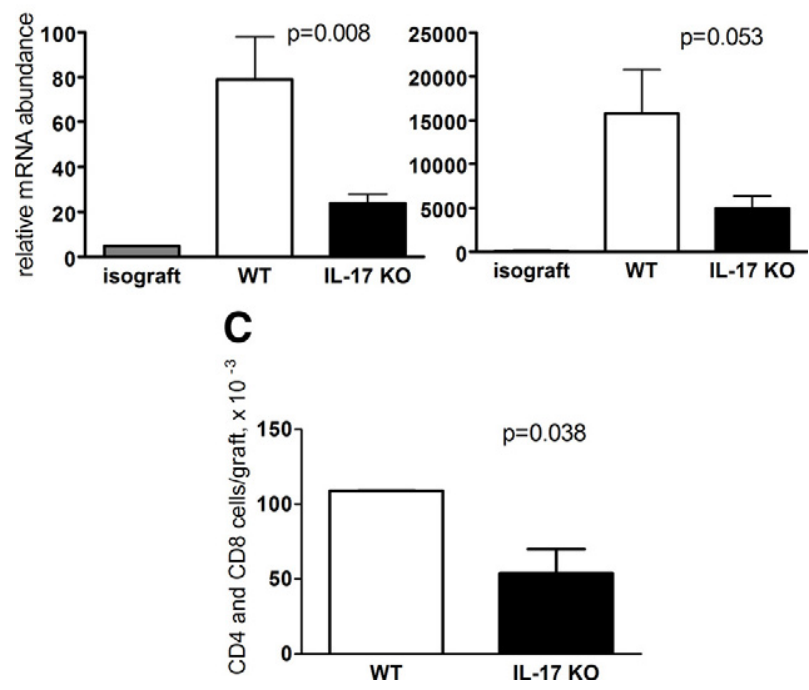

Figure 3. Delayed recruitment of $\mathrm{T}$ cells into cardiac allografts from IL-17 KO recipients. A: Immunohistochemical staining for CD 4 and CD8 T cells on day four after transplant. Arrows indicate positively stained cells. Original magnification, $\times 100$. The sections are representative of six to eight recipients per group. B: Intragraft expression of CD3 (left) and IFN $\gamma$ (right) mRNA in wild-type and IL-17 KO heart allograft recipients. Total RNA was isolated from heart grafts on day four after transplantation, and mRNA levels were measured by real-time RT-PCR. $N=10$ per group. C: Graft infiltrating cells were isolated on day four after transplantation by collagenase digestion and analyzed by flow cytometry. The data represent total numbers of $\mathrm{CD} 4^{+}$and $\mathrm{CD}^{+}{ }^{+}$T cells per graft. $N=3$ per group; experiment was performed twice with similar results.

shown). In accordance with these findings, the numbers of graft infiltrating CD4 T cells in IL-17 KO recipients were significantly lower than those in wild-type mice on day 6 after transplant (the time point when wild-type, but not IL-17 KO, recipients start to reject their grafts; Figure 7B). In contrast, similar numbers of graft infiltrating CD4 T cells, macrophages, and neutrophils were recovered from wild-type and $\mathrm{IL}-17 \mathrm{KO}$ recipients at the time of rejection (Figure $7 \mathrm{~B}$ and data not shown), suggesting that the absence of recipient IL-17 delayed the progression of graft injury. ELISPOT analyses of recipient spleen cells demonstrated that CD8-depleted wild-type and IL-17 KO recipients had similar numbers of donor-reactive IFN $\gamma$ or IL-4-producing CD4 T cells (Figure 7C). These data indicate that the delayed CD4 T cell infiltration in IL-17 KO

A

CD4
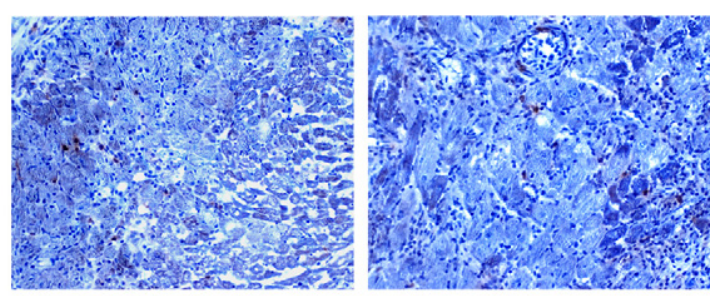

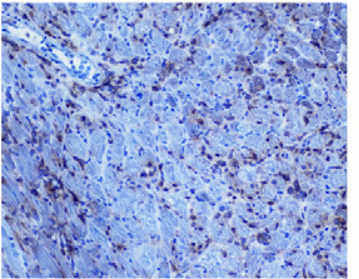

WT recipients

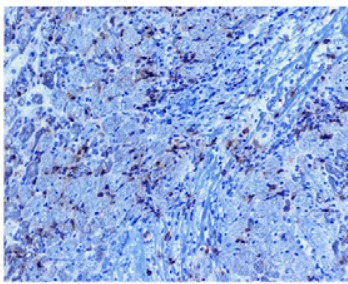

IL-17 KO recipients
B

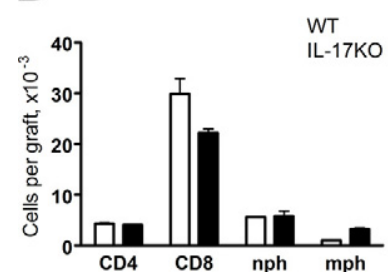

C

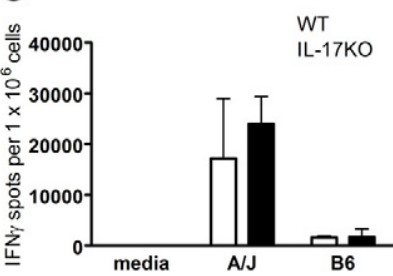

Figure 4. Cardiac allografts from wild-type and IL-17 KO recipients reveal similar intensity and composition of cellular infiltrate on day seven after transplantation. A: Immunohistochemical staining for CD4 and CD8 T cells performed on day seven after transplant. The sections are representative of ten recipients analyzed per group. B: Graft infiltrating cells were isolated on day seven after transplant by collagenase digestion and analyzed by flow cytometry. The numbers of positively stained cells per graft are shown for each subset. $N=4$ animals per group. Each experiment was performed twice with similar results. C: Graft infiltrating cells were tested in a recall IFN $\gamma$ ELISPOT assay against donor A/J or third party B6 stimulator cells.

recipients did not result from inefficient priming of alloreactive $\mathrm{T}$ cells.

\section{IL-17 Promotes Recruitment of Effector CD4 T Cells into the Graft}

Even though the numbers of donor-specific Th1 and Th2 cells were comparable in CD8 depleted wild-type and $\mathrm{IL}-17 \mathrm{KO}$ recipients, it is conceivable that priming in the IL-17 deficient environment alters the ability of T cells to infiltrate into the graft. To distinguish between the sys-

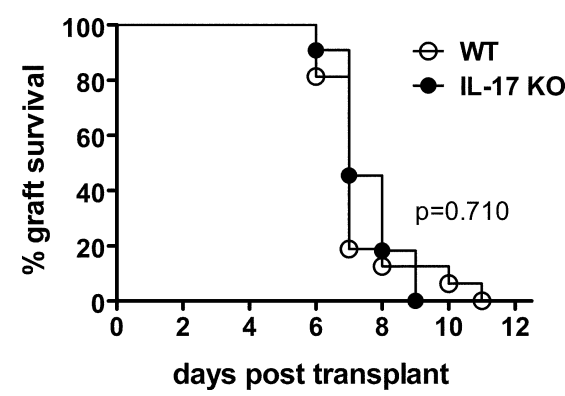

Figure 5. Wild-type and IL-17 KO BALB/c mice reject $\mathrm{A} / \mathrm{J}$ cardiac allografts with similar kinetics. Groups of BALB/c wild-type $(n=16)$ and IL-17 KO $(n=11)$ mice received cardiac allografts from $\mathrm{A} / \mathrm{J}$ donors. The graft survival was monitored daily by abdominal palpation and rejection was confirmed by laparotomy. 
A

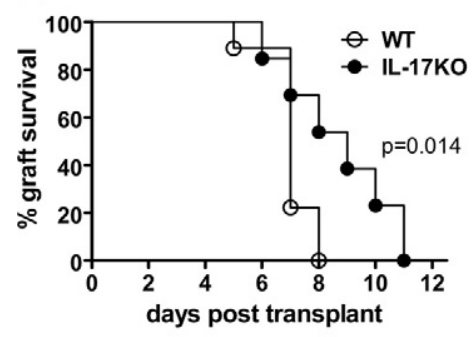

B
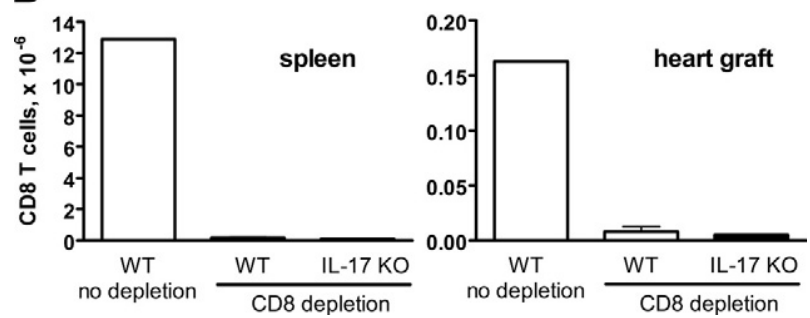

Figure 6. CD4 T cell mediated rejection of cardiac allografts is delayed in IL-17-deficient recipients. Wild-type BALB/c $(n=9)$ and IL-17 KO mice ( $n=$ 13) were treated with CD8-depleting antibodies ( $0.2 \mathrm{mg}$ i.p. on days $-3,-2$, $-1,5$, and 10) and transplanted with $\mathrm{A} / \mathrm{J}$ cardiac allografts (day 0 ). A: Cardiac allograft survival. B and C: Splenocytes (B) and graft-infiltrating cells (C) were stained with anti-CD 8 antibodies and analyzed by flow cytometry. Cells isolated from untreated wild-type $\mathrm{BALB} / \mathrm{c}$ recipients of $\mathrm{A} / \mathrm{J}$ heart grafts served as a control. $N=6$ per group.

temic and local intragraft effects of IL-17 after transplantation, we performed an adoptive transfer of alloreactive effector CD4 $\mathrm{T}$ cells into wild-type or IL-17 KO heart allograft recipients.

Alloreactive effector T cells were generated by placing A/J skin allografts onto wild-type BALB/c recipients. On day 12 after skin transplantation, $T$ cells were isolated from draining lymph nodes, labeled with CFSE, and intravenously injected into wild-type or IL-17 KO mice that have been previously depleted of CD8 T cells and transplanted with $\mathrm{A} / \mathrm{J}$ heart grafts 2 days before effector $\mathrm{T}$ cell transfer. The accumulation of transferred $T$ cells in the graft was assessed 24 hours after cell injection. Although the numbers of $\mathrm{CFSE}^{+} \mathrm{CD}^{+}$cells were comparable in the spleens of wild-type and IL-17 KO mice, infiltration of transferred $\mathrm{T}$ cells into heart allografts was significantly decreased in $\mathrm{IL}-17 \mathrm{KO}$ recipients compared with wildtype recipients (Figure 8 ). Similar to the data presented in Figure $6 \mathrm{~B}$, minimal numbers of $\mathrm{CD}^{+} \mathrm{T}$ cells were present in the periphery or within the graft even after adoptive transfer (data not show). These results indicate that IL-17 facilitates the recruitment of alloantigen-reactive CD4 T cells into the graft tissue regardless of its effect on $T$ cell priming.

\section{Discussion}

Local tissue inflammation is an essential component of acute allograft rejection. Ischemia and reperfusion injury initiates an early inflammatory cascade characterized by intense polymorphonuclear leukocyte infiltration followed by parenchymal tissue damage, up-regulation of $\mathrm{MHC}$ and adhesion molecules, and production of pro-inflam-
A
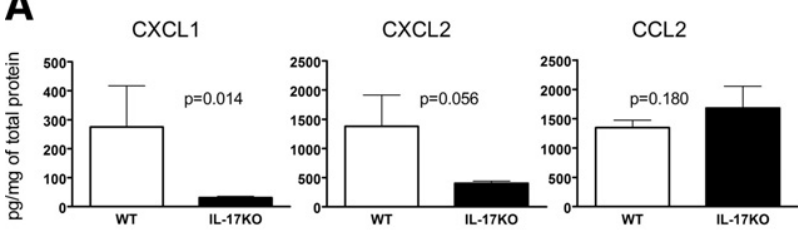

B

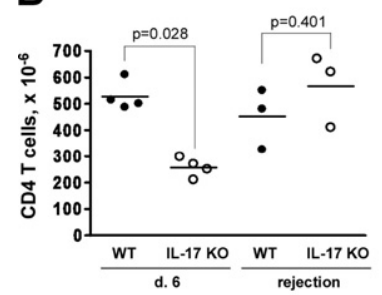

C

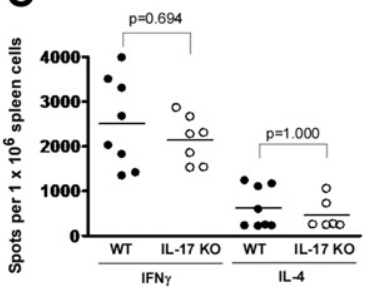

Figure 7. The chemokine expression and the infiltration of activated T cells into the graft is delayed in CD8-depleted IL-17 KO heart allograft recipients despite efficient priming of Th1 and Th2 cells in the spleen. A: Protein lysates were prepared from heart allografts on day four after transplantation and chemokine concentration was measured by enzyme-linked immunosorbent assay. The results are presented as amount of chemokine per milligram of total protein. B: Flow cytometry analysis of graft-infiltrating $T$ cells in wild-type BALB/c and $\mathrm{IL}-17^{-/}$recipients on day six after transplant and at the time of rejection. $\mathbf{C}$. Spleen cells were isolated from wild-type or IL-17 KO recipients of $\mathrm{A} / \mathrm{J}$ heart allografts on day six after transplant and tested in recall IFN $\gamma$ and IL-4 ELISPOT assays against donor (A/J) or third party (B6) stimulator cells. The dots represent responses by individual mice. The number of spots produced in response to third party $\mathrm{B} 6$ cells was $<100 / 1 \times 10^{6}$ for IFN $\gamma$ and $<20 / 1 \times 10^{6}$ for IL- 4 in all recipients. Each experiment was repeated with similar results.

matory cytokines and chemoattractant molecules, which further promote leukocyte trafficking into the graft.

The pro-inflammatory functions of IL-17 are well established. Due to the ubiquitous expression of IL-17R, IL-17 can target various cell types including epithelial and endothelial cells, fibroblasts, and macrophages and or-

\section{A}

AlJ skin graft
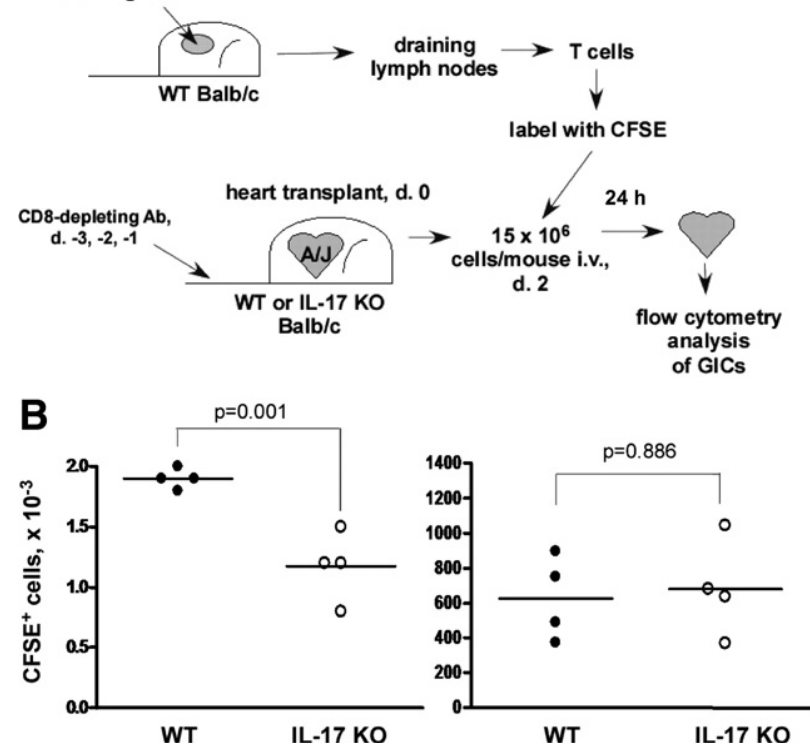

Figure 8. Adoptive transfer of donor-reactive effector T cells into wild-type or IL-17 KO heart allograft recipients. A: Experimental design. B: Wild-type or IL-17 KO heart allograft recipients were sacrificed 24 hours after injection of $15 \times 10^{6}$ CFSE-labeled donor-reactive effector T cells. Spleen and graft infiltrating cells were isolated and analyzed by flow cytometry. The data shown represent total numbers of $\mathrm{CFSE}^{+} \mathrm{CD}^{+}$cells per graft (left) or per spleen (right). 
chestrate tissue inflammation through multiple pathways. A signature downstream effect of IL-17 is the recruitment and activation of neutrophils and monocytes. Among major factors up-regulated by IL-17 are neutrophil- and monocyte-recruiting chemokines (CXCL1, CXCL2, CXCL8, CCL2, and CCL20), pro-inflammatory cytokines (IL-6, tumor necrosis factor $\alpha, \mathrm{IL}-1 \beta$, and granulocyte macrophage colony stimulating factor), costimulatory molecules (CD40 and ICAM-1), and tissue enzymes (matrix metalloproteinases). ${ }^{7,8,10}$ As these molecules are active components of the allograft rejection process, it is conceivable that IL-17 may amplify inflammatory cascades after transplantation and influence graft outcome. However, the role of locally secreted IL-17 in the induction and the course of intragraft inflammation has remained unknown. Our study addressed this question in a model of MHC-mismatched mouse heterotopic cardiac transplantation by using recipients genetically deficient in the expression of IL-17A (IL-17 KO).

In the initial experiments, we observed that allograft placement induced up-regulation of intragraft IL-17 mRNA as early as on day 2, peaking at day 4 after transplant (Figure 1), consistent with previous reports on intragraft IL-17 mRNA and protein expression. ${ }^{19} \mathrm{Al}-$ though cells of the innate immune system, including monocytes, neutrophils, and eosinophils, have been reported to secrete IL-17, IL-17 expression in isografts was only slightly up-regulated suggesting that recognition of donor alloantigen is required for local secretion of this cytokine. In addition, very few IL-17-producing cells were detected by ELISPOT assay within cardiac allografts placed into lymphocyte-deficient BALB/c scid recipients ( $<10$ spots $/ 10^{6}$ GICs compared with $490 \pm 78$ spots $/ 10^{6}$ GICs in wild-type BALB/c recipients on day 6 after transplant). To definitively determine the source of intragraft IL-17, we isolated GICs from A/J heart grafts placed into wild-type BALB/c recipients on day 4 after transplantation and purified cells expressing CD4 or CD8 ( $T$ cells) and CD $4^{-} \mathrm{CD}^{-}$cells (non-T cells) by flow sorting (>98\% purity for each subset). At this time point, $T$ cells represent $\sim 12 \%$ and non-T cells represent $\sim 88 \%$ of total graft infiltrating cells. The isolated cell subsets were tested for the ability to secrete IL-17 by ELISPOT assay. We found that sorted graft-infiltrating T cells produced $\sim 1400 \mathrm{IL}-17$ spots/million of plated cells or $\sim 170$ spots/million of total graft-infiltrating cells in response to stimulation with donor antigen. At the same time, $\mathrm{CD} 4^{-} \mathrm{CD} 8^{-}$cells produced $\sim 600 \mathrm{IL}-17$ spots/million plated cells without additional in vitro stimulation or $\sim 520$ spots/million of total graft-infiltrating cells. Taken together, our data demonstrate that IL-17 is produced by multiple cell subsets within the graft, but its secretion is dramatically amplified by donor-reactive $T$ cells. The molecular requirements for intragraft $\mathrm{IL}-17$ induction by $\mathrm{T}$ cells are currently under investigation in our laboratory.

In addition to donor-reactive $T$ cells, autoreactive $T$ cells activated by allograft placement can secrete IL-17 or induce its production by other cells. A study in a rat model demonstrated that lung isograft injury induced by collagen $\mathrm{V}$-specific $\mathrm{T}$ cells is associated with the secretion of IL-17 and IL-23. ${ }^{35}$ Yet, induction of autoantigen- reactive $T$ cells takes longer than the priming of alloantigen-specific $T$ cell responses. This leaves a possibility that early IL-17 is produced by endogenous memory $T$ cells that are present even in naivve mice, comprise up to $5 \%$ of the total T lymphocyte population, and can infiltrate the graft as early as 24 hours after transplant. ${ }^{32,36-39}$

Recipient IL-17 deficiency did not lead to prominent changes in systemic alloresponse as comparable numbers of donor-reactive T cells secreting IFN $\gamma$ or IL-4 and similar frequencies of $\mathrm{CD} 25^{+} \mathrm{FoxP} 3^{+} \mathrm{CD} 4 \mathrm{~T}$ cells were observed in spleens of IL-17 KO and wild-type recipients on day 7 after transplantation (data not shown). Nonetheless, diminished early expression of CXCL1, CXCL2, and CCL2 and attenuated early PMN infiltration resulted in delayed $\mathrm{T}$ cell recruitment and IFN $\gamma$ expression in the grafts from IL-17 KO mice (Figure 3). However, despite the ameliorated early inflammation, the intensity and composition of cellular infiltrates was comparable in grafts isolated from wild-type and IL-17 KO recipients on day 7 after transplant, and the kinetics of graft loss was similar in both groups (Figures 4 and 5).

The similar rejection rate in wild-type and IL-17 KO recipients was somewhat unexpected considering previously published observations that targeting the IL-17 network leads to improved allograft outcome. ${ }^{24,25,40}$ Recipient treatment with IL-17R-Fc fusion protein was reported to prolong survival of vascularized and nonvascularized cardiac allografts and thoracic aortic allografts in mice. ${ }^{25,40,41}$ In another study, gene transfer of an IL-17R-Ig fusion protein prolonged heart allograft survival in a rat model. ${ }^{24}$ Notably, in all of these cases allograft rejection was delayed for a few days by IL-17 antagonism. The fact that IL-17 deficiency did not prolong allograft survival in our study can be potentially explained by the difference in species and/or transplanted organ, by a higher immunogenicity of the donor strain, or by the use of cytokine deficient recipients versus neutralizing reagents.

Another model in which blocking IL-17 has been reported to improve allograft survival is the use of recipients deficient in the Th1 transcription factor T-bet that reveal exaggerated priming of donor-reactive IL-17-secreting T lymphocytes resistant to conventional costimulatory blockade. Under these conditions, neutralizing IL-17 facilitates heart allograft survival and attenuates the development of vasculopathy. ${ }^{21-23}$ In contrast, graft survival in the current study suggests that in the presence of all arms of the alloimmune response, factors other than IL-17 promote T-cell recruitment and facilitate graft rejection, thereby compensating for the absence of IL-17.

The major event that occurs within the cardiac allograft after 4 days after transplant is the intense recruitment of donor-specific IFN $\gamma$-secreting CD8 T cells that act as major effector cells during allograft rejection. ${ }^{32}$ In addition, IFN $\gamma$ derived from CD8 T cells may directly induce CXCL9, CXCL10, and CXCL11 and further enhance T cell infiltration thus compensating for the lack of IL-17 in our experiments. Consistent with this model, heart allograft rejection mediated by CD4 T Iymphocytes was modestly but significantly delayed in IL-17 KO mice. Despite equal priming of donor-reactive Th1 and Th2 cells in wild-type 
and IL-17 KO allograft recipients, the infiltration of activated CD4 T cells into cardiac allografts was delayed in the absence of IL-17 (Figure 7). Furthermore, the lack of recipient IL-17 resulted in the decreased recruitment of donor-reactive effector T cells activated under IL-17 sufficient conditions, indicating that IL-17 can promote $\mathrm{T}$ lymphocyte trafficking into the graft independent of their priming.

It should be noted that the IL-17 KO mice used in our study express other members of the IL-17 family, including IL-17B, C, D, E, and F. Of these cytokines, IL-17F shares the highest homology to IL-17A and can be produced by Th17 cells. ${ }^{7,42,43}$ Despite similarity in structure and function, IL-17F has been reported to have a weaker pro-inflammatory activity and to regulate different types of in vivo responses than IL-17A. ${ }^{44}$ Previous studies demonstrating the role of $\mathrm{IL}-17$ in transplantation targeted exclusively IL-17A, either through use of IL-17RA fusion proteins (that do not bind to IL-17F) or by specific blocking antibody. This suggests that the contribution of IL-17F in allograft rejection appears to be minor compared with the function of IL-17A.

Based on our findings, we propose that IL-17 produced at the graft site early after transplantation promotes neutrophil recruitment through the induction of chemoattractant mediators thus facilitating further infiltration of donor-reactive T cells into the graft. Nevertheless, our results do not limit the role of $\mathrm{IL}-17$ exclusively to chemokine induction and PMN recruitment. IL-17 upregulates expression of matrix metalloproteinases, such as matrix metalloproteinase- 3,9 , and 13 , that enable neutrophils and activated $T$ cells to migrate through extracellular matrix. ${ }^{45,46}$ Data from animal models of infection suggest other pro-inflammatory effects of intragraft IL-17 such as up-regulation of IL-6 and nitric oxide production and increasing the expression of costimulatory and adhesion molecules such as CD40 and ICAM-1.47-51

In summary, our study identifies IL-17 as an active participant in the early inflammatory cascade following allograft transplantation in fully immunocompetent recipients. The clinical relevance of this information is underscored by studies indicating that IL-17 mRNA and protein are elevated in human renal and lung allografts experiencing acute rejection and by the recent finding that IL-17-secreting cells are resistant to the effects of conventional costimulatory blockade. Our findings on the nature of early allograft inflammation suggest that targeting the IL-17 signaling network in conjunction with other graft-prolonging therapies may improve function and survival of transplanted organs.

\section{Acknowledgments}

We thank Ms. Earla Biekert for expert technical assistance and Dr. Robert Fairchild for the critical reading of the article.

\section{References}

1. Benichou G, Valujskikh A, Heeger PS: Contributions of direct and indirect $\mathrm{T}$ cell alloreactivity during allograft rejection in mice. J Immunol 1999, 162:352-358

2. Dallman MJ, Larsen CP, Morris PJ: Cytokine gene transcription in vascularised organ grafts: analysis using semiquantitative polymerase chain reaction. J Exp Med 1991, 174:493-496

3. Morgan CJ, Pelletier RP, Hernandez CJ, Teske DL, Huang E, Ohye R, Orosz CG, Ferguson RM: Alloantigen-dependent endothelial phenotype and lymphokine mRNA expression in rejecting murine cardiac allografts. Transplantation 1993, 55:919-924

4. Halloran PF, Miller LW, Urmson J, Ramassar V, Zhu LF, Kneteman NM, Solez K, Afrouzian M: IFN-gamma alters the pathology of graft rejection: protection from early necrosis. J Immunol 2001, 166: 7072-7081

5. Konieczny BT, Dai Z, Elwood ET, Saleem S, Linsley PS, Baddoura FK Larsen CP, Pearson TC, Lakkis FG: IFN-gamma is critical for long-term allograft survival induced by blocking the CD28 and CD40 ligand T cell costimulation pathways. J Immunol 1998, 160:2059-2064

6. Miura M, El-Sawy T, Fairchild RL: Neutrophils mediate parenchymal tissue necrosis and accelerate the rejection of complete major histocompatibility complex-disparate cardiac allografts in the absence of interferon-gamma. Am J Pathol 2003, 162:509-519

7. Kolls JK, Linden A: Interleukin-17 family members and inflammation. Immunity 2004, 21:467-476

8. Weaver CT, Hatton RD, Mangan PR, Harrington LE: IL-17 family cytokines and the expanding diversity of effector $T$ cell lineages. Annu Rev Immunol 2007, 25:821-852

9. Hamada S, Umemura M, Shiono T, Tanaka K, Yahagi A, Begum MD Oshiro K, Okamoto Y, Watanabe H, Kawakami K, Roark C, Born WK O'Brien R, Ikuta K, Ishikawa H, Nakae S, Iwakura Y, Ohta T, Matsuzaki G: IL-17A produced by gammadelta $T$ cells plays a critical role in innate immunity against listeria monocytogenes infection in the liver. J Immunol 2008, 181:3456-3463

10. Kolls JK, McCray PB, Jr., Chan YR: Cytokine-mediated regulation of antimicrobial proteins. Nat Rev Neurosci 2008, 8:829-835

11. Matsuzaki G, Umemura M: Interleukin-17 as an effector molecule of innate and acquired immunity against infections. Microbiol Immunol 2007, 51:1139-1147

12. Korn T, Oukka M, Kuchroo V, Bettelli E: Th17 cells: effector T cells with inflammatory properties. Semin Immunol 2007, 19:362-371

13. Tesmer LA, Lundy SK, Sarkar S, Fox DA: Th17 cells in human disease. Immunol Rev 2008, 223:87-113

14. Dardalhon V, Korn T, Kuchroo VK, Anderson AC: Role of Th1 and Th17 cells in organ-specific autoimmunity. J Autoimmun 2008 31:252-256

15. Goverman J: Autoimmune $\mathrm{T}$ cell responses in the central nervous system. Nat Rev Neurosci 2009, 9:393-407

16. Korn T, Bettelli E, Oukka M, Kuchroo VK: IL-17 and Th17 Cells. Annu Rev Immunol 2009, 27:485-517

17. Nalbandian A, Crispin JC, Tsokos GC: Interleukin-17 and systemic lupus erythematosus: current concepts. Clin Exp Immunol 2009, 157:209-215

18. Hsieh HG, Loong CC, Lui WY, Chen A, Lin CY: IL-17 expression as a possible predictive parameter for subclinical renal allograft rejection. Transpl Int 2001, 14:287-298

19. Loong CC, Hsieh HG, Lui WY, Chen A, Lin CY: Evidence for the early involvement of interleukin 17 in human and experimental renal allograft rejection. J Pathol 2002, 197:322-332

20. Vanaudenaerde BM, Dupont LJ, Wuyts WA, Verbeken EK, Meyts I, Bullens DM, Dilissen E, Luyts L, Van Raemdonck DE, Verleden GM: The role of interleukin-17 during acute rejection after lung transplantation. Eur Respir J 2006, 27:779-787

21. Burrell BE, Csencsits K, Lu G, Grabauskiene S, Bishop DK: CD8+ Th17 mediate costimulation blockade-resistant allograft rejection in T-bet-deficient mice. J Immunol 2008, 181:3906-3914

22. Yuan X, Ansari MJ, D'Addio F, Paez-Cortez J, Schmitt I, Donnarumma M, Boenisch O, Zhao X, Popoola J, Clarkson MR, Yagita H, Akiba H, Freeman GJ, lacomini J, Turka LA, Glimcher LH, Sayegh MH: Targeting Tim-1 to overcome resistance to transplantation tolerance mediated by CD8 T17 cells. Proc Natl Acad Sci USA 2009, 106: 10734-10739

23. Yuan X, Paez-Cortez J, Schmitt-Knosalla I, D'Addio F, Mfarrej B, 
Donnarumma M, Habicht A, Clarkson MR, lacomini J, Glimcher LH, Sayegh MH, Ansari MJ: A novel role of CD4 Th17 cells in mediating cardiac allograft rejection and vasculopathy. J Exp Med 2008, 205:3133-3144

24. Li J, Simeoni E, Fleury S, Dudler J, Fiorini E, Kappenberger L, von Segesser LK, Vassalli G: Gene transfer of soluble interleukin-17 receptor prolongs cardiac allograft survival in a rat model. Eur $\mathrm{J}$ Cardiothorac Surg 2006, 29:779-783

25. Tang JL, Subbotin VM, Antonysamy MA, Troutt AB, Rao AS, Thomson AW: Interleukin-17 antagonism inhibits acute but not chronic vascular rejection. Transplantation 2001, 72:348-350

26. Corry RJ, Winn HJ, Russell PS: Primarily vascularized allografts of hearts in mice: the role of $\mathrm{H}-2 \mathrm{D}, \mathrm{H}-2 \mathrm{~K}$, and non- $\mathrm{H}-2$ antigens in rejection. Transplantation 1973, 16:343-350

27. Chen Y, Heeger PS, Valujskikh A: In vivo helper functions of alloreactive memory $\mathrm{CD} 4+\mathrm{T}$ cells remain intact despite donor-specific transfusion and anti-CD40 ligand therapy. J Immunol 2004, 172:5456-5466

28. Valujskikh A, Pantenburg B, Heeger PS: Primed allospecific T cells prevent the effects of costimulatory blockade on prolonged cardiac allograft survival in mice. Am J Transplant 2002, 2:501-509

29. Zhang Q, Chen Y, Fairchild RL, Heeger PS, Valujskikh A: Lymphoid sequestration of alloreactive memory CD4 T cells promotes cardiac allograft survival. J Immunol 2006, 176:770-777

30. Valujskikh A, Heeger P: Enzyme linked immunosorbent spot (ELISPOT) assay for detection of alloreactive cytokine-secreting cells: detailed methods. Graft 2000, 3:250-258

31. El-Sawy T, Belperio JA, Strieter RM, Remick DG, Fairchild RL: Inhibition of polymorphonuclear leukocyte-mediated graft damage synergizes with short-term costimulatory blockade to prevent cardiac allograft rejection. Circulation 2005, 112:320-331

32. Schenk AD, Nozaki T, Rabant M, Valujskikh A, Fairchild RL: Donorreactive CD8 memory $T$ cells infiltrate cardiac allografts within 24-h posttransplant in naive recipients. Am J Transplant 2008, 8:1652-1661

33. Krieger NR, Yin DP, Fathman CG: CD4+ but not CD8+ cells are essential for allorejection. J Exp Med 1996, 184:2013-2018

34. Youssef AR, Otley C, Mathieson PW, Smith RM: Role of CD4+ and CD8 $+T$ cells in murine skin and heart allograft rejection across different antigenic desparities. Transpl Immunol 2004, 13:297-304

35. Yoshida S, Haque A, Mizobuchi T, Iwata T, Chiyo M, Webb TJ, Baldridge LA, Heidler KM, Cummings OW, Fujisawa T, Blum JS, Brand DD, Wilkes DS: Anti-type V collagen lymphocytes that express IL-17 and IL-23 induce rejection pathology in fresh and well-healed lung transplants. Am J Transplant 2006, 6:724-735

36. Haluszczak C, Akue AD, Hamilton SE, Johnson LD, Pujanauski L, Teodorovic L, Jameson SC, Kedl RM: The antigen-specific CD8+ T cell repertoire in unimmunized mice includes memory phenotype cells bearing markers of homeostatic expansion. J Exp Med 2009, 206:435-448

37. Min B, McHugh R, Sempowski GD, Mackall C, Foucras G, Paul WE: Neonates support lymphopenia-induced proliferation. Immunity 2003, 18:131-140

38. Pereira P, Forni L, Larsson EL, Cooper M, Heusser C, Coutinho A:
Autonomous activation of $\mathrm{B}$ and $\mathrm{T}$ cells in antigen-free mice. Eur J Immunol 1986, 16:685-688

39. Schuler T, Hammerling GJ, Arnold B: Cutting edge: IL-7-dependent homeostatic proliferation of $\mathrm{CD} 8+\mathrm{T}$ cells in neonatal mice allows the generation of long-lived natural memory T cells. J Immunol 2004, 172:15-19

40. Antonysamy MA, Fanslow WC, Fu F, Li W, Qian S, Troutt AB, Thomson AW: Evidence for a role of IL-17 in alloimmunity: a novel IL-17 antagonist promotes heart graft survival. Transplant Proc 1999, 31:93

41. Antonysamy MA, Fanslow WC, Fu F, Li W, Qian S, Troutt AB, Thomson AW: Evidence for a role of IL-17 in organ allograft rejection: IL-17 promotes the functional differentiation of dendritic cell progenitors. J Immunol 1999, 162:577-584

42. Moseley TA, Haudenschild DR, Rose L, Reddi AH: Interleukin-17 family and IL-17 receptors. Cytokine Growth Factor Rev 2003, 14:155-174

43. Ye P, Rodriguez FH, Kanaly S, Stocking KL, Schurr J, Schwarzenberger P, Oliver P, Huang W, Zhang P, Zhang J, Shellito JE, Bagby GJ, Nelson S, Charrier K, Peschon JJ, Kolls JK: Requirement of interleukin 17 receptor signaling for lung $\mathrm{CXC}$ chemokine and granulocyte colony-stimulating factor expression, neutrophil recruitment, and host defense. J Exp Med 2001, 194:519-527

44. Yang XO, Chang SH, Park H, Nurieva R, Shah B, Acero L, Wang YH, Schluns KS, Broaddus RR, Zhu Z, Dong C: Regulation of inflammatory responses by IL-17F. J Exp Med 2008, 205:1063-1075

45. Koenders MI, Kolls JK, Oppers-Walgreen B, van den Bersselaar L, Joosten LA, Schurr JR, Schwarzenberger P, van den Berg WB, Lubberts $\mathrm{E}$ : Interleukin-17 receptor deficiency results in impaired synovial expression of interleukin-1 and matrix metalloproteinases 3,9 , and 13 and prevents cartilage destruction during chronic reactivated streptococcal cell wall-induced arthritis. Arthritis Rheum 2005, 52:32393247

46. Sergejeva S, Ivanov S, Lotvall J, Linden A: Interleukin-17 as a recruitment and survival factor for airway macrophages in allergic airway inflammation. Am J Respir Cell Mol Biol 2005, 33:248-253

47. Attur MG, Patel RN, Abramson SB, Amin AR: Interleukin-17 up-regulation of nitric oxide production in human osteoarthritis cartilage. Arthritis Rheum 1997, 40:1050-1053

48. Fossiez F, Djossou O, Chomarat P, Flores-Romo L, Ait-Yahia S, Maat C, Pin JJ, Garrone P, Garcia E, Saeland S, Blanchard D, Gaillard C, Das Mahapatra B, Rouvier E, Golstein P, Banchereau J, Lebecque S: $\mathrm{T}$ cell interleukin-17 induces stromal cells to produce proinflammatory and hematopoietic cytokines. J Exp Med 1996, 183:2593-2603

49. Woltman AM, de Haij S, Boonstra JG, Gobin SJ, Daha MR, van Kooten C: Interleukin-17 and CD40-ligand synergistically enhance cytokine and chemokine production by renal epithelial cells. J Am Soc Nephrol 2000, 11:2044-2055

50. Yao Z, Fanslow WC, Seldin MF, Rousseau AM, Painter SL, Comeau MR, Cohen JI, Spriggs MK: Herpesvirus Saimiri encodes a new cytokine, IL-17, which binds to a novel cytokine receptor. Immunity 1995, 3:811-821

51. Yao Z, Painter SL, Fanslow WC, Ulrich D, Macduff BM, Spriggs MK, Armitage RJ: Human IL-17: a novel cytokine derived from T cells. J Immunol 1995, 155:5483-5486 